\title{
The Author Replies: On Sexism
}

\section{Margaret Piercey}

I would like to thank Stinson for her response to the article "Sexism in the English Language." It was my intention to revive this important discussion, and, therefore, I would now like to respond to some of her points.

First, my stance in the article "Sexism in the English Language" was not that the French language, or any other language, is more sexist or less sexist than the English language. I speak French too and am aware of the gender rules of this language. However, my concern in this article was with the English language only. Comparing English with other languages, as Stinson does in her response, is like comparing apples to oranges. She also seems to suggest that we should not complain about the English language because there are other languages much worse. As well, I would like to point out that "Sexism in the English Language" was written with a particular audience in mind-teachers of English as a second language. Whether or not other languages are more, or less, sexist than English is a topic for another, and I'm sure, quite interesting article.

Second, I disagree with Stinson when she suggests that gender rules have nothing to do with sex or sexism or that gender is not synonymous with sex. What we are talking about here are concepts and terms. Her definitions of these terms are grammatically correct. However, recognizing these concepts as sexist is much more difficult than recognizing language in general as sexist, because it touches on the meaning of these concepts: for example, the situation in which they are used or how they are used. Speakers of English can and do embed their sexist attitudes in the language, and this is what we need to be aware of in the language we teach.

Third, and finally, if we agree that sexism still permeates our world, as Stinson does, then let us consider the culturally loaded implications of masculinity and femininity. These concepts, which indicate gender in English, have positive and negative meanings respectively, as I have already stated in the article "Sexism in the English Language." Do we think that the use of words, like he and she, which refer to male and female (i.e., the sex of a person), are not going to carry the same positive and negative meanings? We are sadly mistaken if we believe this to be the case. Therefore, the use of the pronoun he to mean both sexes when no one sex is specified constitutes a sexist practice because it effectively eliminates half the human race. Why did past male grammarians not choose to use she to mean both sexes from the 
beginning? I submit that the decision to use he was a calculated one that intended to enshrine male superiority in the English language.

I appreciate Stinson's efforts to avoid sexist language and do believe that we have made strides in this area over the past few years, but we are not there yet. I can only hope that this discussion has inspired other ESL professionals to reflect on their own teaching practices, which will ensure the inclusion of non-sexist material, language, and literature. 